\title{
Comprehensive clinical drug information service: first year's experience
}

\author{
D M DAVIES, C H ASHTON, J G RAO, M D RAWLINS, P A ROUTLEDGE, R L SAVAGE, \\ J W THOMPSON, M A ZAR
}

British Medical fournal, 1977, 1, 89-90

\section{Summary}

A comprehensive clinical drug information service, established in the Northern Region in May 1975, is manned by eight doctors-all clinical pharmacologists-and is available 24 hours a day. In the first year of operation 451 inquiries were received, $354(78.5 \%)$ of which were "consultative." Though junior hospital doctors used the service most, almost half of the inquiries about adverse reactions to drugs came from consultants.

\section{Introduction}

The increasing complexity of drugs and drug treatment has led to the creation of drug information services. In the Northern Region an information centre dealing with poisons was first established in 1965, and services concerned with adverse drug reactions were established in 1966 and 1972. Since 1 May 1975, however, we have offered a comprehensive clinical drug information service, which we believe is unique in Britain. We describe our experience during the first year's operation.

\section{Aim and organisation}

Our aim is to provide medical colleagues in the region with clinical information and advice on all aspects of clinical pharmacology, clinical pharmacokinetics, therapeutics, and toxicology. Eight doctors (clinical pharmacologists) take it in turn to operate the service, which is available at any time of the day or night. When on duty they may be reached at work by day or at home by night through the telephone switchboard of the Royal Victoria Infirmary, Newcastle upon Tyne. They are provided with reference material comprising information sheets prepared in the department of pharmacological sciences, standard texts, and reprints and may discuss difficult cases with other

Department of Clinical Pharmacology, Shotley Bridge General Hospital, University Department of Pharmacological Sciences, Newcastle upon Tyne

D M DAVIES, FRCP, senior lecturer and consultant physician C H ASHTON, DM, FRCP, senior lecturer J G RAO, MB, medical registrar

M D RAWLINS, MD, MRCP, professor of clinical pharmacology

P A ROUTLEDGE, MB, MRCP, senior research associate

$R$ L SAVAGE, $M B$, senior research associate

$\mathrm{J} W$ THOMPSON, $M B$, PHD, professor of pharmacology

M A ZAR, MB, DPHIL, lecturer members of the team and consult manufacturers of drugs or chemicals, national poisons information centres, or the editorial office of the Adverse Drug Reaction Bulletin, which holds a large collection of toxicological information. Non-urgent inquiries are received by letter.

For each inquiry the date and time, name and address of the inquirer, the problem, and the advice given are recorded.

\section{Analysis of inquiries}

From 1 May 1975 to 30 April 1976, 451 inquiries were received. Of these, $404(89.6 \%)$ were made by telephone, $162(40 \%)$ of the telephoned calls being received between $5 \mathrm{pm}$ and $9 \mathrm{am}$.

A total of $422(93.6 \%)$ of the inquiries concerned toxicological problems, including acute poisoning and adverse drug reactions and interactions. In 248 cases (55\%) the problem involved drugs, in 144 $(32 \%)$ other chemicals (household and industrial chemicals were prominent), and in $30(6.6 \%)$ plants. Of the remaining inquiries, $26(5 \cdot 8 \%)$ concerned treatment and $3(0 \cdot 6 \%)$ tablet identification.

\section{USERS OF SERVICE}

Acute poisoning accounted for many of the toxicological inquiries, which is reflected in the preponderance of junior hospital doctors among the medical users of the service (see table). Most inquiries about adverse drug reactions, however, came from consultants.

Although we expected our service to be used only by medical practitioners, $79(17.5 \%)$ of the inquiries came from paramedical colleagues, non-medical members of the public services (coroners,

Sources of inquiries received during 1 May 1975 to 30 April 1976

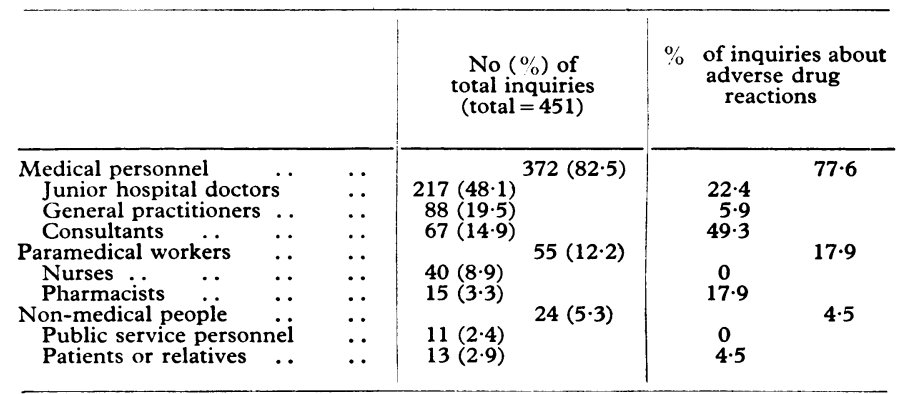

police, firemen, schoolteachers, and social workers) and the general public (13 inquiries; $2.9 \%$ ) (see table). Most of the inquiries (396; $\mathbf{8 7 . 8} \%$ ) came from within the Northern Region, the remainder, except for three from abroad, coming from elsewhere in the UK.

\section{INFORMATION PROVIDED}

DMD and MDR examined the records retrospectively to assess how simple or difficult it had been to provide the information requested. 
The information given was of two types: (1) "factual" replies (97; $21 \cdot 5^{\circ}{ }_{0}$ ), which required only simple statements of fact-for example, the constituents of a drug mixture, the expected pharmacological action of a drug, or common toxic properties of a drug or chemical; and (2) "consultative" replies $\left(354 ; 78.5^{\circ}{ }_{11}\right)$, which required clinical advice on a specific case and usually entailed discussion with the inquirer on the possible benefits and hazards of one or more courses of action in that case.

The type of literature search needed was classified as (1) "none" $\left(158 ; 35.0^{\circ}{ }_{0}\right)$, indicating that members of the team would have been able to give the information and advice from memory; (2) "simple" $\left(197 ; 43 \cdot 7^{\circ}{ }_{0}\right)$, implying that, as judged by the experience of the two analysers, reference to the information sheets or basic texts would have been necessary; and (3) "complex" $96 ;\left(21 \cdot 3{ }^{\prime}{ }_{0}\right)$, indicating that the question would have required a detailed bibliographical search.

\section{Discussion}

We believe that our comprehensive clinical drug information service is unique in Britain in being manned wholly by doctors. The reasons for this lie mainly in its origins-the poisons information service established in $1965^{1}$ at the Royal Victoria Infirmary by the late Dr Nolan Wynne (senior lecturer in pharmacology); Adverse Drug Reaction Bulletin (ADRB), founded by DMD and JWT; and the adverse drug reaction information service established in 1972 within the editorial office of the $A D R B$.

We have drawn the following conclusions from our experience of the service. (1) There is a need for such a service. (2) With a large enough team a 24-hour service may be offered without detriment to the research, teaching, and clinical commitments of the doctors concerned. (3) As most inquiries are consultative -that is, requiring a clinical opinion-they can be managed only by someone with a medical qualification, clinical training, and special expertise in pharmacology. We agree with the view of drug information services taken by the Clinical Pharmacology Committee of the Royal College of Physicians of London ${ }^{2}$ that "if such information and advice is to have an impact it will have to be provided by specialised medical staff." (4) Most inquiries can be answered by experienced clinical pharmacologists without recourse to extensive literature searches (though complex searches, which usually concern adverse drug reactions, are often time-consuming and would be impossible without the facilities of the editorial office of the $A D R B$ ). (5) Even if a drug information service is advertised only to medical colleagues some inquiries will come from the lay public. Most of these are concerned with the toxic potential of certain drugs or chemicals, but some are from or on behalf of patients already suffering the ill effects of drugs. In such cases it has been our policy to advise the inquirer to seek medical advice. (6) A "local" (regional) service has the special benefit of "personal contact"; members of the team and the inquirers are often known to each other and have opportunities to discuss cases together face to face, sometimes at the bedside. Members of the team also gain specialised knowledge of chemicals manufactured locally. (7) We believe that a pharmaceutical component, which we lack, would improve the service, and we plan to correct this deficiency.

We are indebted to Miss Jean Hill, of the Adverse Drug Reaction Bulletin, for help with literature searches, and to Mrs Sylvia Hogg for help in preparing drug information sheets and organising duty rotas.

\section{References}

1 Wynne, N A, Nezcastle Medical fournal, 1968, 30, 78.

"Royal College of Physicians of London. Clinical Pharmacology Committee, Clinical Pharmacology in the Reorganised Health Service. London, RCP, 1974.

(Accepted 18 November 1976)
ONE HUNDRED YEARS AGO Mr Richard Davy's clinical remarks on the dressing of wounds, which appeared in the Journal of December 30th, 1876, are as bold as they are well timed. Mr Davy comes forward as a champion of simplicity and aesthetics in surgical dressing; and, at the present day, when surgeons of the so-called antiseptic school are prone to attribute their success to some special virtue in carbolic acid, or in the way in which they employ it, $\mathrm{Mr}$ Davy's trenchant remarks are of the greatest value.

By their side, I would like to place a few extracts taken from the lectures of a surgeon and teacher of vast and ripe experience. Thus we read in Spence's Lectures on Surgery (vol i, p 140 2nd edition):"Some of the statements advanced in favour of the antiseptic system so ignore the success obtained by simple dressing and treatment of wounds, or assert such an amount of infallibility as to the curative powers of the special method, as to require notice." Such statements, the author considers, arise from want of experience in, or misrepresentation of, the simple method of treating wounds. Further on, he says: "Novelty is not always progress, and unfortunately many novelties in surgery at the present day seem to consist in departure from simplicity of treatment."

The so-called antiseptic method of treatment is held by some of its practitioners to be all but infallible. Indeed, if such an one hear of a case treated "antiseptically" where the issue was unhappy, he is apt to say that there must have been a flaw somewhere in the intricate process. On the other hand, the patient recovers; there the treatment was carried out in its entirety.

$\mathrm{Mr}$ Davy gives us thirty-two cases of important operations without a death, and without any special antiseptic treatment having been adopted. No disciple of any school, however modern, can show better results.

I will now venture to point out how it is that Mr Davy has been so successful in his hospital practice. Like practitioners of the so-called antiseptic method, Mr Davy pays the most careful attention to his patients after operations; he does not leave them (as is often the case in hospital practice) too much to the care of house-surgeons, dressers, and nurses. I speak now with all respect for house-surgeons, but it cannot be denied that they are not always competent to take entire charge of a patient during the critical phases which present themselves in the first few days after an operation. In my experience, there is something for the surgeon to suggest, or to see carried out, each time he sees his patient in the first week, no matter how often he comes. Now this is just where the antiseptic surgeon, in my opinion, effects so much. He is continually seeing his patient. Nothing is left to an untrained assistant or to chance. His dresser is a picked man and is specially instructed. Nothing is neglected; for everything is done in order and under the surgeon's personal and watchful supervision. The time and labour which he gives to his patient meet their due reward.

Ambroise Paré, whom Mr Davy quotes with much effect, used to say of his patient in simple faith: "I dressed him; God cured him." But I apprehend that Paré's watchful care did more for his patients than did his "balsame of boyled whelpes and wormes."

Without presuming to adduce statistics from the work of five or six short years of hospital practice, I would, nevertheless, venture to make a few remarks upon the dressing of wounds. I dislike poultices; sometimes they are applied so hot as to distress the patient considerably. At other times, they are little more than warm. They are always disagreeable and unwholesome. Often the wound is allowed to become chilled whilst a fresh poultice is to be applied. Moist warmth can, when necessary, be obtained in many better ways.

Sores, however foul, may be cleansed and kept absolutely sweet by the liberal use of sulphurous acid lotion, which is of far more value than the fashionable carbolic acid lotion. For the treatment of fresh wounds, nothing is better than dry lint: I have left it on a wound after a herniotomy for three weeks, and, at the end of that time, have found the wound represented by a healthy cicatrix.

As $\mathrm{Mr}$ Davy reminds us, the wound is but a single element in the case, and I apprehend that, if a patient be carefully watched and subjected to well considered hygienic influences, Nature will repair it, unless the interference on the part of the surgeon be too officious. (British Medical Fournal, 1877.) 